\title{
Genome-wide association study identifies loci and candidate genes for non-idiopathic pulmonary hypertension in Eastern Chinese Han population
}

Caiyong Yin ${ }^{1,2+}$, Kai $\mathrm{Li}^{1 \dagger}$, Yanfang Yu' ${ }^{1}$, Huijie Huang ${ }^{1}$, Youjia Yu', Zhongqun Wang ${ }^{3}$, Jinchuan Yan ${ }^{3}$, Yan Pu ${ }^{4}$, Zheng $\mathrm{Li}^{1}$, Ding $\mathrm{Li}^{1}$, Peng Chen ${ }^{1 *}$ (i) and Feng Chen ${ }^{1,5^{*}}$

\begin{abstract}
Background: Pulmonary hypertension $(\mathrm{PH})$ is a rare disease characterized by proliferation and occlusion of small pulmonary arterioles, which has been associated with a high mortality rate. The pathogenesis of PH is complex and incompletely understood, which includes both genetic and environmental factors that alter vascular structure and function.

Methods: Thus we aimed to reveal the potential genetic etiology of PH by targeting 143 tag SNPs of 14 candidate genes. Totally 208 individuals from Chinese Han population were enrolled in the present study, including 109 non-idiopathic PH patients and 99 healthy controls.

Results: The data revealed that 2 SNPs were associated with PH overall susceptibility at $p<3 \times 10^{-4}$ after Bonferroni correction. The top hit was rs6557421 $\left(p=4.5 \times 10^{-9}\right)$, located within Nox3 gene on chromosome 6 . Another SNP rs3744439 located in Tbx4 gene, also showed evidence of association with PH susceptibility $\left(p=1.2 \times 10^{-6}\right)$. The distribution of genotype frequencies of rs6557421 and rs3744439 have dramatic differences between PH patients and controls. Individuals with rs6557421 TT genotype had a 10.72-fold/14.20-fold increased risk to develop PH when compared with GG or GG/GT carriers in codominant or recessive model, respectively (TT versus GG: $95 \% \mathrm{Cl}$ $=4.79-24.00 ; \pi$ versus $\mathrm{GG} / \mathrm{GT}: 95 \% \mathrm{Cl}=6.65-30.33)$. As for rs3744439, $\mathrm{AG}$ genotype only occurred in healthy controls but has not been observed in $\mathrm{PH}$ patients. We further validated the result by using 26 different populations from five regions around the globe, including African (AFR), American (AMR), East Asian (EAS), European (EUR), and South Asian (SAS). In consistent with the present case-control study's results, significantly different genotype frequencies of the observed SNPs existed between PH patients and healthy individuals from all over the world.

Conclusions: The results suggested that rs6557421 variant in Nox3 and rs3744439 variant in Tbx4 might have potential effect on individual susceptibility to pulmonary hypertension, which could lead to therapeutic or diagnosis approaches in $\mathrm{PH}$.
\end{abstract}

Keywords: Pulmonary hypertension, Nox3, Tbx4, GWAS

\footnotetext{
* Correspondence: chenpeng@njmu.edu.cn; fchen@njmu.edu.cn

${ }^{+}$Caiyong Yin and Kai Li contributed equally to this work.

${ }^{1}$ Department of Forensic Medicine, Nanjing Medical University, Nanjing,

Jiangsu 211166, People's Republic of China

Full list of author information is available at the end of the article
}

(c) The Author(s). 2018 Open Access This article is distributed under the terms of the Creative Commons Attribution 4.0 International License (http://creativecommons.org/licenses/by/4.0/), which permits unrestricted use, distribution, and

reproduction in any medium, provided you give appropriate credit to the original author(s) and the source, provide a link to the Creative Commons license, and indicate if changes were made. The Creative Commons Public Domain Dedication waiver (http://creativecommons.org/publicdomain/zero/1.0/) applies to the data made available in this article, unless otherwise stated. 
Table 1 Summarized 14 genes that were analyzed in the present study

\begin{tabular}{|c|c|}
\hline Gene name & The (potential) relationship between the studied genes and PH occurrence. \\
\hline Solute carrier family 4 member 4 (SLC4A4, also known as NBCe1) & $\begin{array}{l}\text { SLC4A4 encodes NBCe1 which is the first eukaryotic } \mathrm{Na}^{+} \text {- coupled transporter. The } \\
\text { transporter is a member of the anion exchange family belonging to the second } \\
\text { largest secondary carrier superfamily (APC). A previous GWAS study have revealed } \\
\text { that SLC4A4 was hypertension susceptibility gene [12]. }\end{array}$ \\
\hline NADPH oxidase 3 (Nox3) & $\begin{array}{l}\text { Nox3 is a member of the NADPH oxidase (Nox) family of oxidant-generating } \\
\text { enzymes. After its original cloning and detection in fetal tissues and inner ear, studies } \\
\text { remain limited and its function mostly limited to gravity perception. However, several } \\
\text { studies have also reported the physiologic role of Nox3 induction in lungs and lung } \\
\text { endothelial cells }[7,13] \text {. }\end{array}$ \\
\hline
\end{tabular}

Interleukin 6 (IL6)

Transcription factor EC (TFEC)

Caveolin-1

NADPH oxidase 4 (Nox4)

Oxidized low density lipoprotein receptor 1 (OLR-1)

Thrombospondin 1 (THBS1)

ATPase phospholipid transporting 8B4 (ATP8B4)

NADPH oxidase 5 (Nox5)

T-box4 (Tbx4)

Chromobox 7 (CBX7)

Cytochrome b-245 beta chain (CYBB)

Galectin-3 (Gal-3)
Interleukin 6 (IL6) is a pleiotropic cytokine with a wide range of biologic function on hematopoiesis, inflammation, immune regulation and oncogenesis. The increasing levels of IL-6 in lung and serum are associated with PH [3].

Transcription factor EC (TFEC) most likely acts as a transcriptional repressor in heterodimers with other microphthalmia-TFE (MiT) family members. The expression of murine TFEC is restricted to macrophages (mTFEC). mTFEC as a macrophage-specific transcription factor plays a critical role in macrophage-specific gene regulation [3]. Considering the activities of macrophages in PH development, TFEC might have potential connection with PH.

Caveolin-1, which is a major protein constituent of caveolae, interacts with a variety of signaling molecules implicated in PH. Disruption and progressive loss of endothelial caveolin-1 with reciprocal activation of proliferative pathways occur before the onset of $\mathrm{PH}$, and the rescue of caveolin-1 inhibits proliferative pathways and attenuates $\mathrm{PH}$ [4].

NADPH oxidase 4 is the major NADPH oxidase homolog expressed in human PASMCs and its expression both at the mRNA and protein level is significantly increased in lungs from patients with $\mathrm{PH}$, which suggests a correlation between Nox4 and the onset of PH $[5,6]$. Additionally, Nox4 acts as a primary source of ROS, contributes to the proliferation and remodeling of $\mathrm{PH}[7,8]$.

Oxidized low density lipoprotein receptor 1 (OLR-1), the receptor for oxidized low-density lipoprotein, is expressed in endothelial cells, macrophages or smooth muscle cells. Recent studies have shown that OLR-1 is involved in the lung inflammation and injury [3]

Thrombospondin 1 (THBS1) is a kind of matricellular protein, which is a secreted molecular that has both extracellular matrix and cell surface receptor. In animals, pulmonary THBS1 is upregulated rapidly following hypoxic challenge. Additionally, clinical studies of plasma THBS1 and mutations of THBS1 in PH have been reported [4].

ATPase phospholipid transporting 8B4 (ATP8B4) activity is important in ATP biosynthesis and phospholipid transport via a variety of potential mechanisms. A recent whole-exome sequencing research identified that ATP8B4 gene is strongly associated with the risk of development of PH [5]

NADPH oxidase 5 (Nox5) is the last NOX family member to be identified. Caveolin-1 binds directly to Nox5 and suppresses the activity of Nox5. Although the direct connection between Nox5 and PH has not been reported, dysregulation of caveolin-1 has been documented with PH states.

T-box4 (Tbx4) is a transcription factor in the T-box gene family, which is expressed in variety of organs including mesenchyme of the lung and trachea. Tbx 4 has been shown to be involved in lung growth and branching. The function mutations in Tbx4 have been previously reported to be associated with PH [3].

Chromobox 7 (CBX7) is one of the five mammalian orthologues of Drosophila Polycomb. CBX7 was recognized as the main orthologue of Drosophila Polycomb implicated in maintaining the self-renewal of embryonic stem cells. Until now, litter is known about the potential correlation of $\mathrm{CBX7}$ to $\mathrm{PH}$.

The Cytochrome b-245 beta chain (CYBB) gene encodes membrane protein Nox2, which plays a crucial role in stromal interaction molecular 1 (STIM1) activation and in the control of the cytosolic oscillations that drive murine pulmonary microvascular endothelial cells (MPMVECS) activation [4]. Our recent research has also revealed the role of STIM1 during the acute lung intoxication [5].

Galectin-3 (Gal-3) is a $\beta$-galactoside binding lectin that regulates multiple pathways. Our recent study has revealed the effectiveness of genetic and pharmacological strategies targeting Gal-3 in halting the progression of $\mathrm{PH}$ remodeling and development of experimental PH [1]. 


\section{Background}

Pulmonary hypertension $(\mathrm{PH})$ is a rare disease characterized by proliferation and occlusion of small pulmonary arterioles, leading to progressive elevation of pulmonary artery pressure, pulmonary vascular resistance, and right ventricular failure [1]. There are 3 subtypes of $\mathrm{PH}$ according to the National Organization for Rare Disorders (NORD), including heritable pulmonary hypertension $(\mathrm{HPH})$, idiopathic pulmonary arterial hypertension (IPH) and associated pulmonary hypertension (APH) [2]. More than half of the $\mathrm{PH}$ patients are non-idiopathic $\mathrm{PH}$, which are also known as secondary PH. During the present study, we focused on the genetic susceptibility of non-idiopathic PH. Revealing the genetic etiology of non-idiopathic PH would facilitate diagnosis and development of novel therapies in the future. During the present study, we reviewed and screened several candidate genes that are potentially or directly associated with $\mathrm{PH}$ occurrence (Table 1).

In summary, these genes were shown to be associated or potentially related with $\mathrm{PH}$ development though the molecular mechanism had not been well understood. To further clarify the association and reveal the candidate functional variants, we conducted the limited scale genome wide association study. One hundred forty-three tag SNPs were screened from the sequences between the upstream and downstream $2 \mathrm{~Kb}$ of the 14 studied genes. The screening population data are from Chinese Han population in Beijing ( $\mathrm{CHB})$ of the Hapmap Project (NCBI build 36, dbSNPb126) and the candidate SNPs were screened by using Haploview software.

\section{Methods \\ Samples}

Totally 208 individuals were enrolled in the present study, including 109 non-idiopathic $\mathrm{PH}$ patients and 99 healthy controls. Patients were consecutively recruited from the Affiliated Hospital of Jiangsu University between May 2014 and July 2016. Clinical information was obtained from medical records, including gender, age, drink, smoke and coronary artery disease (CAD) history and so on. Baseline profiles of the studied population were summarized in Table 2. None of the patients have connective tissue diseases, HIV infection, portal hypertension, congenital heart diseases or thyroid dysfunction. The control subjects were collected from healthy volunteers who visited the Sir Run Run Hospital Nanjing Medical University for medical examination during the same period. The study was performed with the approval of the ethics committee of the Nanjing Medical University and the informed consent was obtained from each participant.

\section{Experimental design and Genotyping}

Genomic DNA was extracted from $200 \mu \mathrm{l}$ EDTAanticoagulated peripheral blood using a commercial extraction kit (Tiangen Biotech Corporation, Beijing, China) according to the instruction manual. The 143 tag SNPs in $109 \mathrm{PH}$ patients were firstly genotyped by using Illumina $\mathrm{X}-10$ platform, and the sequencing was done by commercial company (Decode Genomics BioTech Co., Ltd, Nanjing, China). The genotyping results were then compared with healthy individuals from Southern Han Chinese (CHS) population of 1000G database. And 2 SNPs emerged at a significant level $(P$ $<3 \times 10^{-4}$ ) (Fig. 1). To confirm the finding, we further genotyped 2 SNPs in 99 healthy individuals from Nanjing, Jiangsu by performing fluorescent PCR and Ligase detection reaction (LDR). The primers were designed by using Primer 3 online software version 0.4.0 (http:// frodo.wi.mit.edu/) and Oligo software version 6.3.1 (Molecular Biology Insights, USA). The SNPs were amplified in a final volume of $20 \mu \mathrm{l}$ that contained $50 \mathrm{ng}$ of DNA, $2 \mu \mathrm{l} 1 \times$ buffer, $0.6 \mu \mathrm{l} 3 \mathrm{mM} \mathrm{Mg} 2+, 2 \mu \mathrm{l}$ $2 \mathrm{mM}$ dNTP, $0.2 \mu \mathrm{l}$ Taq DNA polymerase $(1 \mathrm{unit} / \mu \mathrm{l})$ and appropriate concentrations of primers. The PCR reaction

Table 2 Demographic and clinical characteristics of the subjects

\begin{tabular}{|c|c|c|}
\hline & Patients & Controls \\
\hline \multicolumn{3}{|l|}{ Sex } \\
\hline Male & $50(0.46)$ & $63(0.62)$ \\
\hline Female & $59(0.54)$ & $36(0.38)$ \\
\hline Age (y) & $74.07 \pm 12.86$ & $37.26 \pm 9.18$ \\
\hline Systolic PAP (mmHg) & $60.67 \pm 12.73$ & \\
\hline \multicolumn{3}{|l|}{ Drink } \\
\hline Yes & $6(0.06)$ & \\
\hline No & $103(0.94)$ & \\
\hline \multicolumn{3}{|l|}{ Smoke } \\
\hline Yes & $16(0.15)$ & \\
\hline No & $93(0.85)$ & \\
\hline \multicolumn{3}{|l|}{ Coronary heart disease } \\
\hline Yes & $66(0.60)$ & \\
\hline No & $43(0.40)$ & \\
\hline \multicolumn{3}{|l|}{ Heart failure (HF) } \\
\hline Yes & $17(0.15)$ & \\
\hline No & $92(0.84)$ & \\
\hline \multicolumn{3}{|l|}{ Echocardiogram } \\
\hline $\mathrm{LA}(\mathrm{mm})$ & $48.62 \pm 10.58$ & \\
\hline LvIDd (mm) & $52.18 \pm 9.77$ & \\
\hline IVSD (mm) & $10.60 \pm 4.80$ & \\
\hline LVEF (\%) & $57.85 \pm 15.40$ & \\
\hline
\end{tabular}

PAP pulmonary artery pressure, $L A$ atrial diameter, $L v I D d$ left ventricular end diastolic diameter, IVST interventricular septal thickness, LVEF left ventricular ejection fraction 


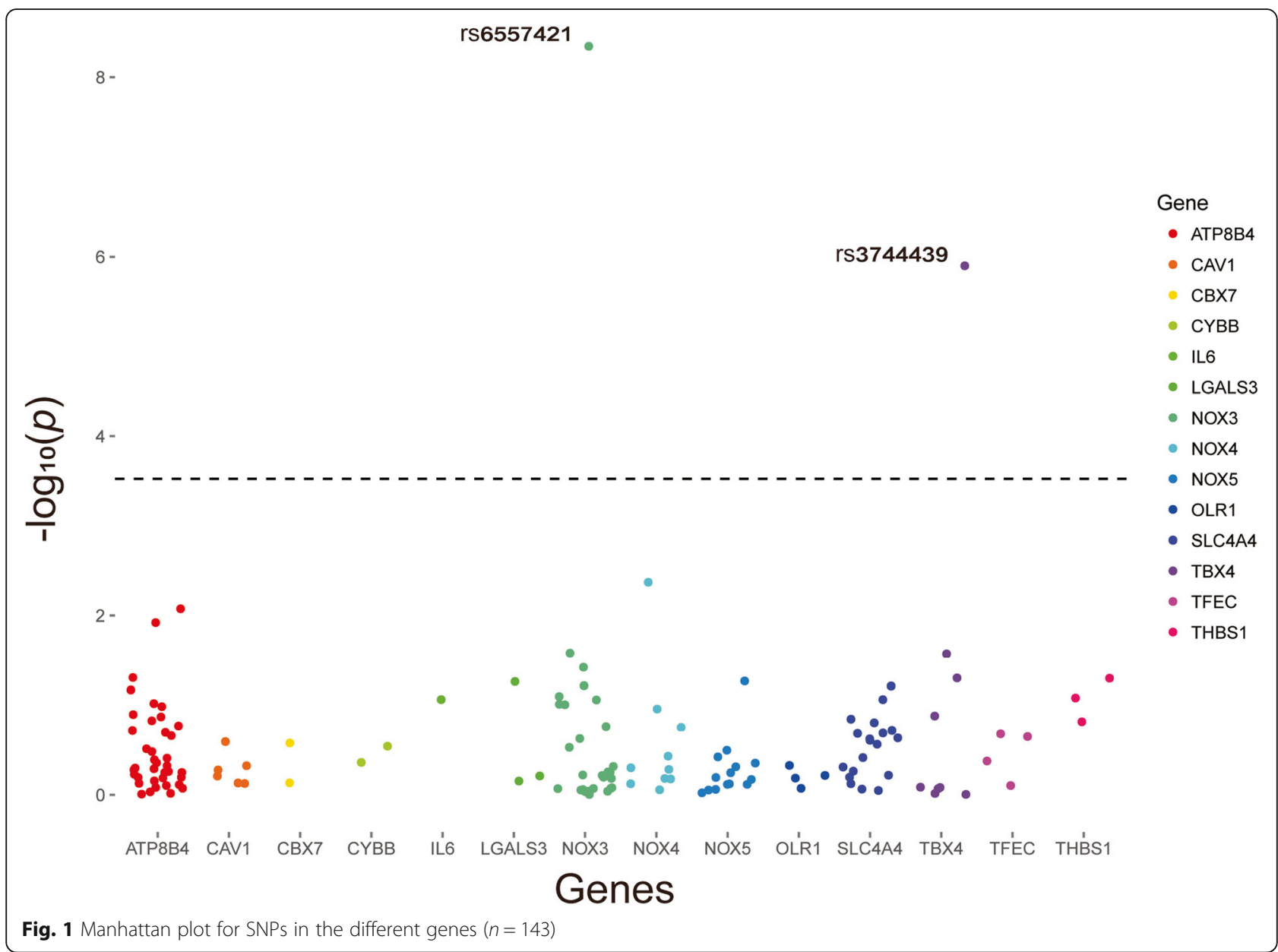

was subjected to an initial denaturation at $95^{\circ} \mathrm{C}$ for $2 \mathrm{~min}$, followed by 40 cycles of amplification consisting of denaturation at $94{ }^{\circ} \mathrm{C}$ for $30 \mathrm{~s}$, annealing at $53{ }^{\circ} \mathrm{C}$ for $90 \mathrm{~s}$, extension at $65{ }^{\circ} \mathrm{C}$ for $30 \mathrm{~s}$, followed by final extension at $65^{\circ} \mathrm{C}$ for $10 \mathrm{mim}$. The LDR was carried out on the PRISM 3730 DNA analyzer (Thermo Fisher Scientific, USA). The LDR were performed in a total volume of $10 \mu \mathrm{l}$ that contained $4 \mu \mathrm{l}$ PCR production, $1 \mu \mathrm{l} 1 \times$ buffer, $1 \mu \mathrm{l}$ probe mix, $0.05 \mu \mathrm{l}$ Taq DNA polymerase $(2$ unit/ $\mu \mathrm{l})$. The LDR condition was $95{ }^{\circ} \mathrm{C}$ for $2 \mathrm{mim}$, followed by 40 cycles of $15 \mathrm{~s}$ at $94{ }^{\circ} \mathrm{C}$ and $25 \mathrm{~s}$ at $50{ }^{\circ} \mathrm{C}$. The SNPs were further genotyped by using Genemapper.

\section{Statistical analysis}

All data were analyzed by using SPSS 19 (SPSS Inc., Chicago, IL). Genotype frequencies of SNPs were obtained by directed computing. Genotypic association analyses in a case-control pattern assuming codominant, dominant, recessive and overdominant genetic models were performed using SNPstats [3]. Odds ratio (OR) and respective $95 \%$ confidence interval were reported to evaluate the effects of any differences between allele and genotype frequencies.

\section{Results}

Candidate SNP selection

Totally 143 SNPs were successfully genotyped in 109 $\mathrm{PH}$ patients. After comparing the genotyping results with the data generated from 105 individuals from Southern Han Chinese population in 1000G database, the results demonstrated that 2 SNPs were associated with $\mathrm{PH}$ with overall susceptibility at $p<3 \times 10^{-4}$ after Bonferroni adjustment. The related analysis was shown in Fig. 1. The top hit was rs6557421 ( $p=$ $4.5 \times 10^{-9}$ ), which is located in Nox3 gene on chromosome 6. Another SNP rs3744439 located in Tbx4 gene, also showed evidence of association with $\mathrm{PH}$ susceptibility $\left(p=1.2 \times 10^{-6}\right)$.

We further genotyped the 2 SNPs in 99 healthy control subjects. The distribution of genotype frequencies of rs6557421 and rs3744439 was illustrated in Fig. 2. Dramatic differences existed between $\mathrm{PH}$ patients and controls. As shown in Table 3, individuals with rs6557421 TT genotype had a 10.72-fold/14.20-fold increased risk to develop PH when compared with GG or GG/GT carriers in codominant or recessive model, respectively (TT versus $\mathrm{GG}$ : $95 \% \mathrm{CI}=4.79-24.00$; $\mathrm{TT}$ versus $\mathrm{GG} / \mathrm{GT}$ : 


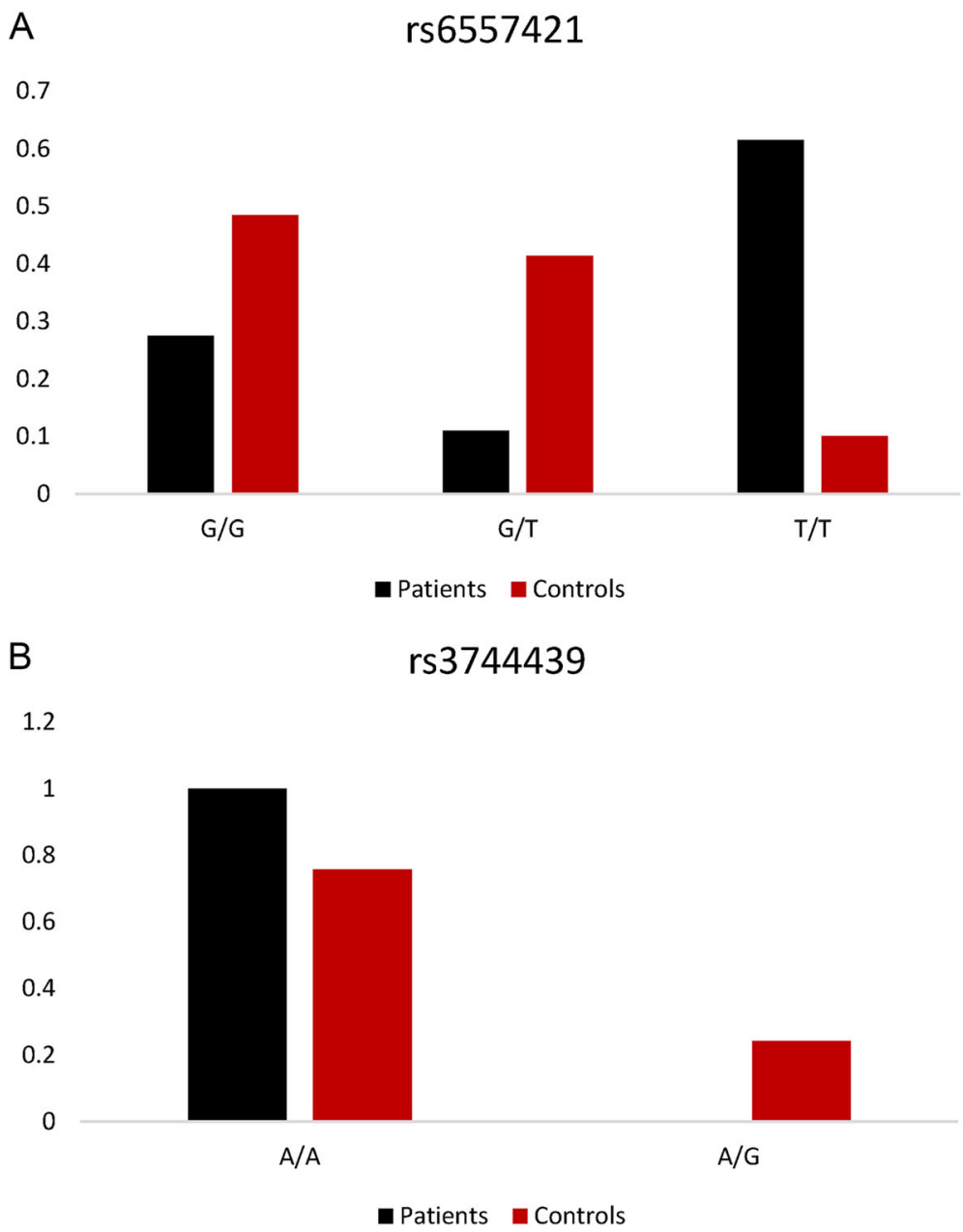

Fig. 2 The distribution of genotype frequencies of Nox3 rs6557421 (a) and Tbx4 rs3744439 (b) among PH patients and healthy controls

Table 3 Genotype frequencies of rs6557421 in Nox3 gene among PH patients and controls

\begin{tabular}{|c|c|c|c|c|c|c|c|}
\hline \multirow[t]{2}{*}{ Genetic model } & \multirow[t]{2}{*}{ Genotype } & \multirow{2}{*}{$\begin{array}{l}\text { Patients } \\
N=109(\%)\end{array}$} & \multirow{2}{*}{$\begin{array}{l}\text { Controls } \\
N=99(\%)\end{array}$} & \multicolumn{2}{|l|}{ Logistic regression } & \multicolumn{2}{|c|}{ Logistic regression (adjusted) } \\
\hline & & & & OR $(95 \% \mathrm{Cl})$ & $P$-value & $\mathrm{OR}^{c}(95 \% \mathrm{Cl})$ & $P$-value \\
\hline \multirow[t]{3}{*}{ Codominant } & GG & $30(27.5)$ & $48(48.5)$ & 1.00 & & 1.00 & \\
\hline & GT & $12(11)$ & $41(41.4)$ & $0.47(0.21-1.03)$ & $<0.0001$ & $0.22(0.03-1.66)$ & 0.0001 \\
\hline & $\pi$ & $67(61.5)$ & $10(10.1)$ & $10.72(4.79-24.00)$ & & $9.66(1.82-51.28)$ & \\
\hline \multirow[t]{2}{*}{ Dominant } & GG & $30(27.5)$ & $48(48.5)$ & 1 & & 1.00 & \\
\hline & $\mathrm{GT} / \mathrm{TT}$ & $79(72.5)$ & $51(51.5)$ & $2.48(1.39-4.41)$ & 0.0018 & $2.02(0.53-7.74)$ & 0.3 \\
\hline \multirow[t]{2}{*}{ Recessive } & GG/GT & $42(38.5)$ & 89 (89.9) & 1.00 & & 1.00 & \\
\hline & $\Pi$ & $67(61.5)$ & $10(10.1)$ & $14.20(6.65-30.33)$ & $<0.0001$ & $17.29(3.60-83.02)$ & 0.0001 \\
\hline \multirow[t]{2}{*}{ Overdominant } & $\mathrm{GG} / \mathrm{TT}$ & $97(89)$ & $58(58.6)$ & 1.00 & & 1.00 & \\
\hline & GT & $12(11)$ & $41(41.4)$ & $0.18(0.09-0.36)$ & $<0.0001$ & $0.08(0.01-0.48)$ & 0.0013 \\
\hline
\end{tabular}

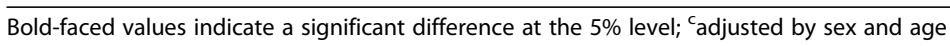


$95 \% \mathrm{CI}=6.65-30.33)$. In dominant model, significantly increased $\mathrm{PH}$ susceptibility was associated with GT/TT genotypes compared with GG genotype $(\mathrm{OR}=2.48$, $95 \% \mathrm{CI}=1.39-4.41)$. Furthermore, dramatically decreased $\mathrm{PH}$ risk was associated with GT genotype when compared with GG/TT genotypes in an overdominant model.

As shown in Fig. 2b and Table 4, rs3744439 AG genotype only occurred in healthy controls which had not been observed in $\mathrm{PH}$ patients.

Stratification analysis was also performed, and $\mathrm{PH}$ patients were divided into three groups according to the Nox3 rs6557421 genotypes. The distribution of patients' left atrial diameter (LA), left ventricular end diastolic diameter (LvIDd), interventricular septal thickness (IVST), left ventricular ejection fraction (LVEF) and systolic pulmonary artery pressure (PAP) were compared between each groups (Fig. 3). No significant differences were observed among different genotyping groups.

\section{Comparison between different populations around globe} We further validated the observation by using 26 different populations from five regions around the globe, including African (AFR), American (AMR), East Asian (EAS), European (EUR), and South Asian (SAS). As illustrated in Fig. $4 \mathrm{a}$ and $\mathrm{b}$, the distribution of rs6557421 and rs3744439 genotypes' frequencies of control group from Chinese Han population was quite similar to which from Asian populations. In consistent to the present case-control study's results, significantly different genotype frequencies existed between $\mathrm{PH}$ Patients and healthy individuals from all over the world (Fig. 4a and b).

\section{Discussion}

Among NADPH oxidases, Nox3 seems to have the most restricted expression pattern in the mammalian organism. Nox3 is specifically localized to the inner ear. Thus the previous studies mostly focused on the unique function of Nox3 involving in the biogenesis of otoconia/otolith [4]. However, few studies have revealed the potential critical role of Nox3 in the pathophysiological process of $\mathrm{PH}$ development. Nox3 is the predominant source of palmitate-induced ROS generation [5]. Nox3 activation during ischemia-reperfusion injury may contribute to the development of primary graft dysfunction after lung transplantation [6]. Upregulated Nox3 leads to increased oxidant generation and elastolytic activity, resulting in increased oxidant injury and death in mice and lung endothelial cells [7]. Treatment of $\mathrm{Tlr}^{-1-}$ mice or endothelial cells with Nox3 siRNA or chemical NADPH inhibitors could reverse the phenotype [7]. Overall, the studies identified that Nox3 could be a potential therapeutic target in the lungs.

The present case-control study revealed that a Nox3 tagSNP rs6557421 had a significantly association with the $\mathrm{PH}$ susceptibility. When random individuals carry rs6557421 TT genotype, they have nearly 10-fold increased risk to develop PH when compared with GG or GG/GT carriers. Moreover, GT genotype carriers have a significantly decreased $\mathrm{PH}$ risk compared with GG/TT genotype carriers. To further investigate the racial disparities, we enrolled 26 populations from 1000G to make a comparison. All the populations from different continents possessed relatively low frequency of TT genotype $\quad(\mathrm{AFR}=0.006, \quad \mathrm{AMR}=0.052, \quad \mathrm{EAS}=0.113$, $\mathrm{EUR}=0.056$, SAS $=0.08$, Han in present $=0.101$ ). On the contrary, the proportion of TT genotype carriers in $\mathrm{PH}$ patients reached 0.615 . The data indicated that TT genotype might be associated with increased $\mathrm{PH}$ in different races.

Mutations in Tbx4 have been proved to be associated with $\mathrm{PH}$ onset [8]. Tbx4 shows high specific expression in lung fibroblasts and broadly regulates fibroblastrelated pathway that partly contributes to superenhancer-mediated transcriptional programs [9]. Decreased Tbx4 in the pulmonary mesenchyme during fetal lung development may lead to the decrease or arrest of airway branching, thus contributing to $\mathrm{PH}$ [10]. Tbx4 was also regarded as a mesenchymal transcription factor that drove myofibroblasts accumulation and the development of lung fibrosis [11].

Our research revealed that Tbx4 rs3744439 had a significant association with $\mathrm{PH}$ risk. The frequencies of AG genotype in present control Chinese Han population and other 26 populations around the globe are all over than 0.10 (Han in present $=0.24$, AFR $=$ $0.23, \mathrm{AMR}=0.19, \mathrm{EAS}=0.17, \mathrm{EUR}=0.10, \mathrm{SAS}=0.14$ ). Interestingly, during the $\mathrm{PH}$ patients, $\mathrm{AG}$ and $\mathrm{GG}$ genotype frequencies were 0 . The data suggested that

Table 4 Genoetype frequencies of rs3744439 in Tbx4 gene among PH patients and controls

\begin{tabular}{|c|c|c|c|c|c|c|c|}
\hline \multirow[t]{2}{*}{ Genetic model } & \multirow[t]{2}{*}{ Genotype } & \multirow{2}{*}{$\begin{array}{l}\text { Patients } \\
N=109(\%)\end{array}$} & \multirow{2}{*}{$\begin{array}{l}\text { Controls } \\
N=99(\%)\end{array}$} & \multicolumn{2}{|c|}{ Logistic regression } & \multicolumn{2}{|c|}{ Logistic regression (adjusted) } \\
\hline & & & & $\mathrm{OR}(95 \% \mathrm{Cl})$ & $P$-value & $\mathrm{OR}^{c}(95 \% \mathrm{Cl})$ & $P$-value \\
\hline & AA & $109(100)$ & $75(75.8)$ & 1.00 & & 1.00 & \\
\hline & $A G$ & $0(0)$ & $24(24.2)$ & $0.00(0.00-\mathrm{NA})$ & $<0.0001$ & $0.00(0.00-\mathrm{NA})$ & 0.0013 \\
\hline
\end{tabular}

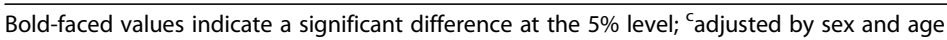




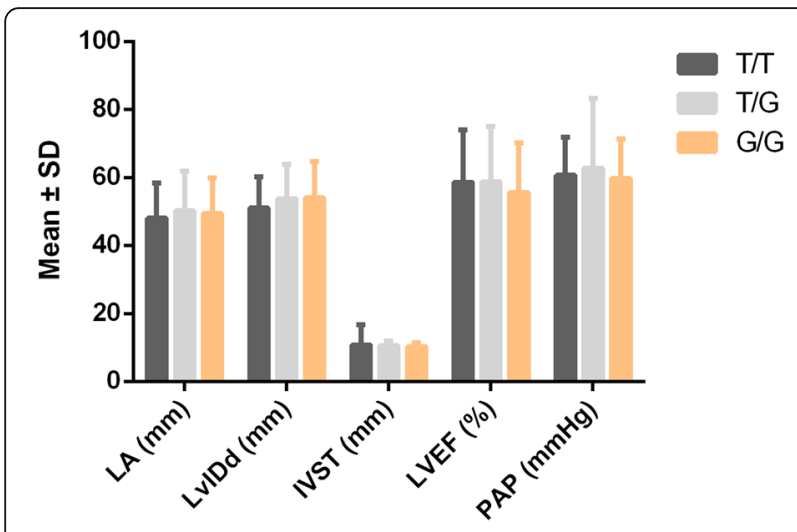

Fig. 3 The distribution of patients' left atrial diameter ( $L A)$, left ventricular end diastolic diameter (LVIDd), interventricular septal thickness (IVST), left ventricular ejection fraction (LVEF) and systolic pulmonary artery pressure (PAP) among different genotypes of Nox3 rs655742
AG genotype could be a protective factor for the $\mathrm{PH}$ development.

The present study has an obvious limitation. As noted in the Methods section that the ages of patients and controls are significantly different. The controls are younger, and they might develop $\mathrm{PH}$ in the future. Considering the relative low incidence of $\mathrm{PH}$, we believe the results are reliable. To further validate the results, healthy independent individuals from 1000G database were also included. And the results were consistent.

\section{Conclusions}

In summary, it is biologically plausible that rs6557421 variant in Nox3 and rs3744439 variant in Tbx4 may have potential effects on individual susceptibility to pulmonary hypertension, which could lead to therapeutic or diagnosis approaches in $\mathrm{PH}$.

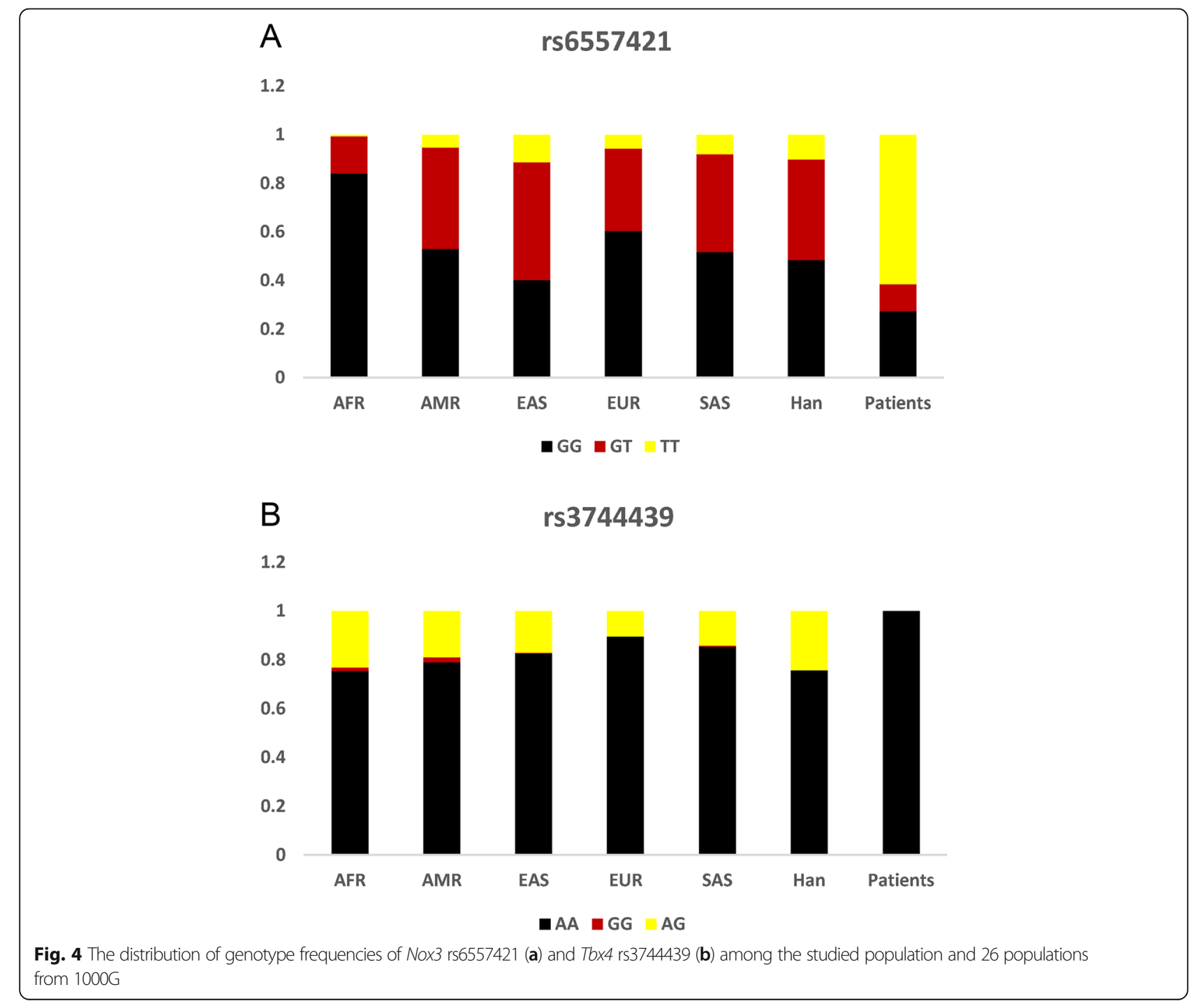




\section{Abbreviations}

ATP8B4: ATPase phospholipid transporting 8B4; CHX7: Chromobox 7; CYBB: Cytochrome b-245 beta chain; IL6: Interleukin 6; NORD: National Organization for Rare Disorders; Nox3: NADPH oxidase 3; Nox4: NADPH oxidase 4; Nox5: NADPH oxidase 5; OLR-1: Oxidized low density lipoprotein receptor 1; PH: Pulmonary hypertension; SLC4A4: Solute carrier family 4 member 4; Tbx4: T-box4; TFEC: Transcription factor EC; THBS1: Thrombospondin 1

\section{Funding}

This work was supported by the National Natural Science Foundation of China (No.81570378, No.81772020 and No.81801879), the Science and Technology of Jiangsu Province China (BK20170048 and BK20161034), and Jiangsu SpeciallyAppointed Professor program. The National Natural Science Foundation of China, the Science and Technology of Jiangsu Province China and Jiangsu Specially-Appointed Professor program played no role in the design of the study and collection, analysis, and interpretation of data and in writing the manuscript.

\section{Availability of data and materials}

The datasets used and analyzed during the current study are available from the corresponding author on reasonable request.

\section{Authors' contributions}

FC and PC designed the study and were major contributors in writing the manuscript. KL, ZQW and JCY collected samples of patients and controls. YFY, HJH and YJY performed the experiments. CYY, YP, ZL and DL analyzed and interpreted the data. All authors read and approved the final manuscript.

\section{Ethics approval and consent to participate}

The study was performed with the approval of the ethics committee of the Nanjing Medical University and the written informed consent was obtained from each participant.

\section{Consent for publication}

Not applicable.

\section{Competing interests}

The authors declare that they have no competing interests.

\section{Publisher's Note}

Springer Nature remains neutral with regard to jurisdictional claims in published maps and institutional affiliations.

\section{Author details}

'Department of Forensic Medicine, Nanjing Medical University, Nanjing, Jiangsu 211166, People's Republic of China. ${ }^{2}$ MOE Key Laboratory of Contemporary Anthropology, Department of Anthropology and Human Genetics, School of Life Sciences, Fudan University, Shanghai 200438, People's Republic of China. ${ }^{3}$ Department of Cardiology, Affiliated Hospital of Jiangsu University, Zhenjiang, Jiangsu 212001, People's Republic of China.

${ }^{4}$ School of Medicine, Southeast University, Nanjing, Jiangsu 210009, People's Republic of China. ${ }^{5}$ Key Laboratory of Targeted Intervention of Cardiovascular Disease, Collaborative Innovation Center for Cardiovascular Disease Translational Medicine, Nanjing Medical University, Nanjing, Jiangsu 211166 People's Republic of China.

Received: 3 June 2018 Accepted: 6 September 2018 Published online: 05 October 2018

\section{References}

1. Barman SA, Chen F, Li X, Haigh S, Stepp DW, Kondrikov D, Mahboubi K, Bordan Z, Traber P, Su Y, Fulton DJR. Galectin-3 promotes vascular remodeling and contributes to pulmonary hypertension. Am J Respir Crit Care Med. 2018:197:1488-92.

2. Soubrier F, Chung WK, Machado R, Grunig E, Aldred M, Geraci M, Loyd JE, Elliott CG, Trembath RC, Newman JH, Humbert M. Genetics and genomics of pulmonary arterial hypertension. J Am Coll Cardiol. 2013;62:D13-21.

3. Sole X, Guino E, Valls J, Iniesta R, Moreno V. SNPStats: a web tool for the analysis of association studies. Bioinformatics. 2006;22:1928-9.
4. Zhang X, Shan P, Jiang G, Cohn L, Lee PJ. Toll-like receptor 4 deficiency causes pulmonary emphysema. J Clin Invest. 2006;116:3050-9.

5. Garcia-Redondo AB, Aguado A, Briones AM, Salaices M. NADPH oxidases and vascular remodeling in cardiovascular diseases. Pharmacol Res. 2016;114:110-20

6. Cantu E, Shah RJ, Lin W, Daye ZJ, Diamond JM, Suzuki Y, Ellis JH, Borders CF, Andah GA, Beduhn B, et al. Oxidant stress regulatory genetic variation in recipients and donors contributes to risk of primary graft dysfunction after lung transplantation. J Thorac Cardiovasc Surg. 2015;149:596-602.

7. Zhang Y, Shan P, Srivastava A, Jiang G, Zhang X, Lee PJ. An endothelial Hsp70-TLR4 axis limits Nox3 expression and protects against oxidant injury in lungs. Antioxid Redox Signal. 2016;24(17):991-1012.

8. Zhu N, Gonzaga-Jauregui C, Welch CL, Ma L, Qi H, King AK, Krishnan U, Rosenzweig EB, Ivy DD, Austin ED, et al. Exome sequencing in children with pulmonary arterial hypertension demonstrates differences compared with adults. Circ Genom Precis Med. 2018;11:e001887.

9. Horie M, Miyashita N, Mikami Y, Noguchi S, Yamauchi Y, Suzukawa M, Fukami T, Ohta K, Asano Y, Sato S, et al. TBX4 is involved in the superenhancer-driven transcriptional programs underlying features specific to lung fibroblasts. Am J Physiol Lung Cell Mol Physiol. 2018;314:L177-|191.

10. Takahashi T, Friedmacher F, Zimmer J, Puri P. Expression of T-box transcription factors 2, 4 and 5 is decreased in the branching airway mesenchyme of nitrofen-induced hypoplastic lungs. Pediatr Surg Int. 2017; 33:139-43.

11. Xie T, Liang J, Liu N, Huan C, Zhang Y, Liu W, Kumar M, Xiao R, D'Armiento J. Metzger D, et al. Transcription factor TBX4 regulates myofibroblast accumulation and lung fibrosis. J Clin Invest. 2016;126:3063-79.

12. Yang HC, Liang YJ, Chen JW, Chiang KM, Chung CM, Ho HY, Ting CT, Lin TH, Sheu SH, Tsai WC, Chen JH, Leu HB, Yin WH, Chiu TY, Chern CL, Lin SJ, Tomlinson B, Guo Y, Sham PC, Cherny SS, Lam TH, Thomas GN, Pan WH. dentification of IGF1, SLC4A4, WWOX, and SFMBT1 as hypertension susceptibility genes in Han Chinese with a genome-wide gene-based association study. Plos One. 2012;7(3):e32907.

13. Wang $H$, Albadawi $H$, Siddiquee $Z$, Stone JM, Panchenko MP, Watkins MT, Stone JR. Altered vascular activation due to deficiency of the NADPH oxidase component p22phox. Cardiovasc Pathol. 2014;23(1):35-42

\section{Ready to submit your research? Choose BMC and benefit from:}

- fast, convenient online submission

- thorough peer review by experienced researchers in your field

- rapid publication on acceptance

- support for research data, including large and complex data types

- gold Open Access which fosters wider collaboration and increased citations

- maximum visibility for your research: over $100 \mathrm{M}$ website views per year

At $\mathrm{BMC}$, research is always in progress.

Learn more biomedcentral.com/submissions 